Review

\title{
Topical PDT in the Treatment of Benign Skin Diseases: Principles and New Applications
}

\author{
Miri Kim, Haw Young Jung and Hyun Jeong Park* \\ Department of Dermatology, Yeouido St. Mary's Hospital, The Catholic University of Korea, \\ Seoul 150-713, Korea; E-Mails: gimmil@hanmail.net (K.M.); myparable@naver.com (H.Y.J.) \\ * Author to whom correspondence should be addressed; E-Mail: hjpark@catholic.ac.kr; \\ Tel.: +82-2-3779-1230; Fax: +82-2-783-7604.
}

Academic Editor: Michael R. Hamblin

Received: 23 July 2015 / Accepted: 22 September 2015 / Published: 25 September 2015

\begin{abstract}
Photodynamic therapy (PDT) uses a photosensitizer, light energy, and molecular oxygen to cause cell damage. Cells exposed to the photosensitizer are susceptible to destruction upon light absorption because excitation of the photosensitizing agents leads to the production of reactive oxygen species and, subsequently, direct cytotoxicity. Using the intrinsic cellular heme biosynthetic pathway, topical PDT selectively targets abnormal cells, while preserving normal surrounding tissues. This selective cytotoxic effect is the basis for the use of PDT in antitumor treatment. Clinically, PDT is a widely used therapeutic regimen for oncologic skin conditions such as actinic keratosis, squamous cell carcinoma in situ, and basal cell carcinoma. PDT has been shown, under certain circumstances, to stimulate the immune system and produce antibacterial, and/or regenerative effects while protecting cell viability. Thus, it may be useful for treating benign skin conditions. An increasing number of studies support the idea that PDT may be effective for treating acne vulgaris and several other inflammatory/infective skin diseases, including psoriasis, rosacea, viral warts, and aging-related changes. This review provides an overview of the clinical investigations of PDT and discusses each of the essential aspects of the sequence: its mechanism of action, common photosensitizers, light sources, and clinical applications in dermatology. Of the numerous clinical trials of PDT in dermatology, this review focuses on those studies that have reported remarkable therapeutic benefits following topical PDT for benign skin conditions such as acne vulgaris, viral warts, and photorejuvenation without causing severe side effects.
\end{abstract}


Keywords: photodynamic therapy; topical photosensitizer; benign skin disease; acne vulgaris; wart; photorejuvenation

\section{Introduction}

The principle of photodynamic action was first described by Oscar Raab in 1890 when he noted the toxic effects of acridine orange, which showed activity as a photosensitizer when combined with light and oxygen by destroying Paramecium caudatum cells without apparent damage to the protozoa when used alone [1]. Von Tappeiner discovered in 1903 that the administration of eosin following irradiation with light led to oxygen-dependent tissue reactions and improvements in skin diseases such as condylomata lata, lupus vulgaris, psoriasis, syphilis, and skin cancers [2]. He termed this activity a "photodynamic reaction". In the late 1970s, photodynamic therapy (PDT) with hematoporphyrin derivative (HPD) was developed by Thomas Dougherty and his co-workers. They purified HPD to some extent and discovered that the administration of HPD followed by irradiation with red light resulted in oxygen-dependent tissue reactions [3].

Today, it is known that PDT relies on the absorption of harmless visible light by a photosensitizer, which then produces reactive oxygen species (ROS) such as singlet oxygen that destroy cancer cells, blood vessels, and pathogenic microorganisms. Currently, topical PDT is being widely used to treat actinic keratosis, and it has been studied for the treatment and prevention of superficial skin cancers in immunosuppressed patients for over 40 years. Additionally, the range of off-label indications has been expanding continuously.

Topical photosensitizers are used mainly in the field of dermatology because they can be delivered directly to the skin and rarely cause prolonged phototoxicity, a known side effect of systemic photosensitizers. Topical PDT is a new and rapidly evolving therapeutic option for the treatment of inflammatory skin diseases, such as psoriasis, acne vulgaris, and sarcoidosis, as well as infectious skin diseases, including verruca vulgaris, condyloma acuminatum, and cutaneous leishmaniasis [4-9].

Recent publications have reviewed the roles of PDT in precancerous skin lesions and superficial skin cancers $[10,11]$. In this review, we summarize the underlying principles in the use of PDT for dermatological conditions and discuss the clinical evidence for the use of topical PDT in treating acne vulgaris, photodamaged skin, and human papillomavirus infections, such as warts.

\section{Mechanism of Action of Photodynamic Therapy (PDT)}

Generally, PDT requires three essential components for the biochemical process to proceed: a photosensitizer, an appropriate light source, and tissue oxygen. The photosensitizer is a photosensitive molecule that is localized within the target tissue and is activated by a specific wavelength or energy of light. When the photosensitizer is exposed to light of the appropriate wavelength, it is activated from the ground state, $\mathrm{S} 0$, to the first excited state, $\mathrm{S} 1$.

The excited photosensitizer goes from S0 to S1 and undergoes intersystem crossing to the long-lived metastable triplet state that then transfers hydrogen or energy to ground state $\mathrm{O}_{2}$. This activated photosensitizer can then undergo two types of reaction in which the energy released can mediate 
selective cell killing. First, it can react directly with a substrate, such as intracellular molecules or cell membrane components, to form radicals, which then interact with oxygen to generate ROS (type I reaction); Second, the activated photosensitizer can transfer its energy directly to oxygen to form the ROS singlet oxygen $\left({ }^{1} \mathrm{O}_{2}\right)$, which further oxidizes various substrates (type II reaction). These species can oxidize various substrates and initiate cytotoxic effects by inducing necrosis and apoptosis. The generation of singlet oxygen species by type II photochemical reactions is believed to be the predominant reaction in PDT. At low levels of PDT, biological systems may be positively stimulated by low enhancement of ROS levels.

With blue light, activation of the Soret band causes the photosensitizer to go to S2 (the second electronically excited state). It then undergoes internal conversion to S1, after which one may either get fluorescence, further internal conversion to S0, or intersystem crossing to give the metastable triplet state which can either react with surrounding molecules (by $\mathrm{H}$ atom transfer) or transfer its excitation energy to ground (triplet) state oxygen to make single oxygen.

Beyond direct phototoxic effects on target tissues, PDT can stimulate diverse immune cells and inflammatory cell mediators, whereas the inverse was stated above. Immune-specific responses during PDT include the production of various cytokines, such as interleukin (IL)-1- $\beta$, IL-2, and tumor necrosis factor- $\alpha$; matrix metalloproteinase (MMP)-1 and MMP-3 are also secreted by fibroblasts in response to PDT $[12,13]$. Following a low light dose, PDT with various photosensitizers has been shown to modify cytokine expression and induce immune-specific responses, resulting in immunomodulatory effects in inflammatory skin disorders.

\section{PDT Components}

\subsection{Photosensitizer}

In the mid-1900s, most photosensitizers used in PDT were derivatives of hematoporphyrin, an endogenous porphyrin that is formed in the first step of the heme biosynthetic pathway. Because large amounts of hematoporphyrin are required for photosensitization, the endogenous porphyrin can cause severe phototoxicity and prolonged and pronounced photosensitivity. Kennedy et al. developed a topical photosensitizer precursor, 5-aminolevulinic acid (ALA), in 1990, and this overcame many of the limitations of earlier PDT [14]. Currently, the most commonly used precursors of protoporphyrin IX (PPIX) in dermatology are topical 5-ALA, methyl-ALA (MAL), and other intermediate photosensitizing porphyrins. After topical application of the photosensitizer precursor, an "occlusion time" is permitted for the drug to be metabolized and for porphyrins to accumulate before activation with visible light. The advantages of topical PDT are the ability to treat multiple lesions simultaneously, low invasiveness, good tolerance, and excellent cosmetic results.

Given the ease with which photosensitizers and light can be delivered to the skin, it is not surprising that PDT is increasingly used as a therapy in dermatology. PDT is now used widely for the treatment of various skin tumors and infectious or inflammatory skin disorders. 


\subsubsection{5-Aminolevulinic Acid (ALA)-Induced Protoporphyrin IX (PPIX)}

The application of ALA in PDT for skin disorders was first introduced in 1990 [14]. The main advantage of topical ALA-PDT is the absence of systemic cutaneous photosensitivity. The molecule 5-ALA is an amino acid and a precursor of PPIX. Topically applied ALA enters into cells of the epidermis and its appendages and is converted endogenously via the porphyrin pathway into PPIX, the active photosensitizing compound $[14,15]$. PPIX selectively accumulates in malignant cells, as well as in epidermal cells, sebaceous glands, and hair follicles [16].

Kennedy et al. observed that ALA applied topically in aqueous solution passed readily through abnormal keratin and was taken up more by altered keratinocytes than by normal keratinocytes [14]. Moreover, porphyrin biosynthesis is increased in malignant or premalignant cells, which means that PPIX photosensitization can be selectively induced in the abnormal epithelium [17]. After irradiating light within the action spectrum (including 400-410 and $635 \mathrm{~nm}$ ), PPIX is activated and generates singlet oxygen or ROS, which cause selective cellular damage including damage to the plasma membrane, mitochondria, and endoplasmic reticulum [18].

ALA is available commercially as Levulan $^{\circledR}$ (DUSA Pharmaceuticals, Wilmington, MA, USA), which is a $20 \%$ 5-ALA solution in alcohol and is currently approved in combination with blue light for the treatment of nonhyperkeratotic actinic keratosis of the face and scalp in North America [18]. In Europe, ALA is available in the form of a patch containing ALA and a gel formulation of ALA in a nanoemulsion. It is also licensed for the treatment of actinic keratosis in combination with red light. The fact that ALA is a water-soluble amino acid, has low lipid solubility, and is unable to penetrate through the stratum corneum restricts its clinical application in PDT to superficial skin diseases such as actinic keratosis, Bowen's disease, and superficial basal cell carcinoma (BCC) $[19,20]$.

To enhance ALA delivery to target tissues, novel preparations of ALA, particularly nanoparticulate delivery vehicles, have been developed [21]. These nanoemulsion formulations can increase liposomal penetration and more selectively transport ALA to target tissues. ALA-PDT using nanoemulsion formulations has been recently shown to be superior to MAL-PDT in the treatment of actinic keratosis, with complete clearance rates of $78.2 \%$ and $64.2 \%$, respectively [22].

\subsubsection{ALA-Ester-Induced PPIX}

As a doubly charged molecule, ALA does not easily pass through cell membranes. Esterified derivatives of ALA that increase the lipophilicity of 5-ALA, such as MAL, butyl-ALA and hexyl-ALA, could potentially enhance penetration of the cell membrane and lead to more homogeneous tissue distribution of PPIX [23]. Once they have penetrated in the tissue, the ALA esters will be cleaved (hydrolysed) by the esterases present in the tissue and thus returned to active 5-ALA.

A methyl ester of ALA, MAL is a more recently introduced topical photosensitizer precursor used in the treatment of nonmelanoma skin cancer, including BCC and squamous cell cancer. When applied topically, MAL is metabolized into a photoactive porphyrin, PPIX, by a mechanism similar to that of ALA.

MAL is available in a cream containing $168 \mathrm{mg} / \mathrm{g}$ of MAL (final MAL concentration of 16.8\%) and is marketed as Metvix ${ }^{\circledR}$ (Galderma, Fort Worth, TX, USA) for the treatment of actinic keratosis and, 
depending on the country, for squamous cell carcinoma in situ and superficial and nodular BCC considered unsuitable for surgical procedures in Europe, Australia, and South America. In the United States, MAL is marketed as Metvix ${ }^{\circledR}$ and is currently FDA approved for the treatment of nonhyperkeratotic actinic keratosis of the face and scalp in immunocompetent patients.

Many clinical trials studying the use of MAL, including phase III randomized controlled studies of MAL-PDT, support the utility of MAL-PDT in the treatment of malignant skin cancers [24-27]. Compared with ALA, MAL is a more lipid-soluble derivative because it is more lipophilic and therefore has a deeper skin penetration. However, there was no statistically significant difference in efficacy between ALA and MAL in the treatment of nodular BCC in one small pilot study or in the treatment of actinic keratosis in another randomized trial [28-30]. In theory, MAL may be more selective than ALA in its affinity for lipophilic environments, such as sebum, and thus would be expected to have greater efficacy in the treatment of acne [31].

\subsubsection{Other Topical Photosensitizers}

Other photosensitizers that have been studied as alternatives to ALA and MAL include hypericin, chlorophyll, indocyanine green (ICG), and indole-3-acetic acid (IAA) [32-34]. Hypericin, a naturally occurring photosensitizer, is extracted from Hypericum perforatum plants. Hypericin-PDT has been shown to be effective in the treatment of dermatophytes, such as Candida spp. and Trichophyton spp. [35].

Chlorophyll has a structure similar to protoporphyrinogen IX and acts as a photosensitizer when it binds to magnesium [36]. The absorption spectrum of chlorophyll ranges from 400 to $700 \mathrm{~nm}$ and shows two absorbance peaks at 415 and 630-664 nm [37]. Compared with ALA or MAL, chlorophyll has the advantages of being cost-effective, with a relatively short incubation time, and the ability to act as a photosensitizer in a shorter time. Chlorophyll may play an important role as a convenient alternative treatment modality for patients with acne who are intolerant to conventional therapies. Kim et al. conducted a split-face study of acne in Asian patients in which they compared the use of PDT with intense pulsed light (IPL) after 30 min of 19\% a,b-chlorophyll solution incubation and IPL alone [34]. Chlorophyll also has several practical advantages, including shorter incubation times and cheaper cost, while having equivalent efficacy. Chlorophyll-based PDT appears to be able to reduce sebum excretion.

Jang et al. performed a comparative split-face, single-blind, clinical trial of PDT with ICG and IAA for the treatment of acne vulgaris. Thirty-four patients with acne were treated with IAA with green light $(520 \mathrm{~nm})$ on half of the face and with ICG with near-infrared radiation $(805 \mathrm{~nm})$ on the other half five times at 1-week intervals [38]. There were significant reductions in acne lesions in both treatment groups compared with the baseline. They concluded that PDT with either ICG or IAA is effective in the treatment of inflammatory and noninflammatory acne.

\subsection{Light Sources for Topical PDT}

It is important to choose an appropriate light source by considering the optimal photosensitizer to be used in PDT. To achieve the most efficient therapeutic effect of PDT, the selection of appropriate light with a proper wavelength corresponding to the area of the maximal porphyrin-activation spectrum in tissues is important. PPIX following ALA or MAL application has a strong absorption peak at $405 \mathrm{~nm}$ 
in the Soret band area of the spectrum $(\sim 405-420 \mathrm{~nm})$ along with several smaller Q bands; the last peak is at $635 \mathrm{~nm}$.

Multiple light sources, including light-emitting diodes (LEDs), Argon ion pumped dye lasers, simple slide projector lamps, and other broadband light devices, such as IPLs and pulsed dye lasers (PDLs), are used in PDT.

The wavelength of blue light ranges from 410 to $420 \mathrm{~nm}$ with a peak wavelength of $417 \mathrm{~nm}$, which corresponds to the area of maximum PPIX light absorption. In the dermatology field, ALA-PDT with blue light for the treatment of actinic keratosis is one of the most widely accepted applications. Blue light sources, including BLU-U ${ }^{\circledR}$ (DUSA Pharmaceuticals, Wilmington, MA, USA) and ClearLight ${ }^{\circledR}$ (Lumenis, Santa Clara, CA, USA) systems, are FDA-approved devices. These blue light devices have FDA approval for the treatment of mild-to-moderate inflammatory acne vulgaris [39].

Longer wavelengths of light, such as red light, are desirable for thicker lesions, such as in Bowen's disease or BCC. Because red light does not excite PPIX as intensely as blue light, a higher fluence is needed, usually $75-100 \mathrm{~J} / \mathrm{cm}^{2}$, depending on the bandwidth of the light source.

Several other light sources that correspond to the action spectrum of PPIX are used, including IPLs, PDLs $(585 \mathrm{~nm})$, and natural sunlight. IPL, which provides a range of wavelengths of light, and flash lamp-pumped PDLs are efficient in activating PPIX [40]. The benefits of these light sources over blue light are the time efficiency, the possibility of accumulating pulses, and the possible improvement in treating associated vascular and pigmented lesions within the broad treatment of the lesions.

Side effects that may occur with PDT include erythema, swelling, ulceration, burning, or prickly sensation in PDT-treated sites [41] (Figure 1). Pain is most common side effect of topical PDT and may be often severe. This can be avoided nearly completely by lowering the fluence rate $\left(\mathrm{mW} / \mathrm{cm}^{2}\right)[42,43]$.
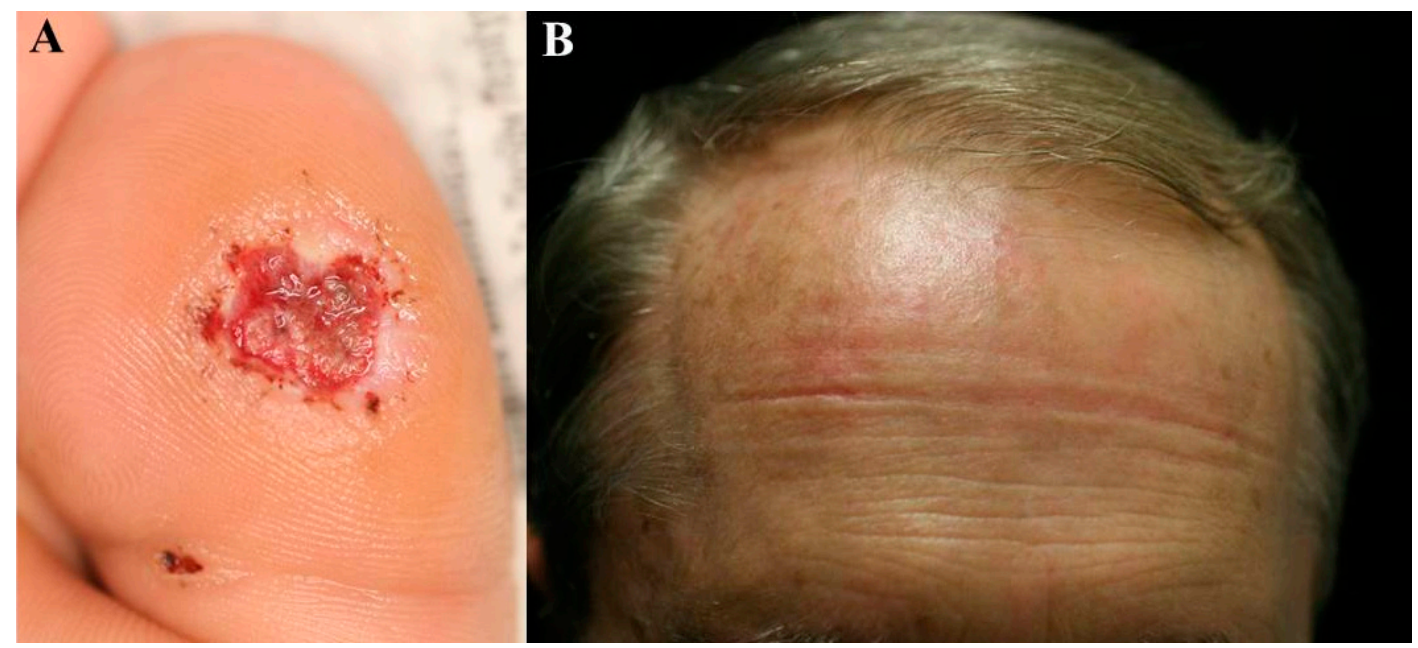

Figure 1. Side effects of PDT treatments. (A) Ulceration on the great toe after treatment of a wart with ILI-PDT; and (B) Diffuse mild erythema on the forehead after first treatment session of actinic keratosis with chlorophyll-PDT. ILI: intralesional injection; PDT: photodynamic therapy. 


\section{Therapeutic Applications of PDT in Benign Skin Diseases}

\subsection{PDT for Acne Vulgaris}

Acne vulgaris is a chronic inflammatory skin disease that is characterized by excessive growth of bacteria such as Propionibacterium acnes in the sebaceous glands [44,45]. It commonly affects the face during adolescence and can lead to emotional, social, and psychological concerns such as anxiety, reduced self-esteem, and depression. Thus, the selection of the appropriate treatment option for each patient with acne vulgaris is important. The ideal treatment for acne vulgaris is an agent with antibacterial activity against Propionibacterium acnes and anti-inflammatory and seboregulating properties. Many treatment modalities are used to treat acne, including oral/topical antibiotics and retinoids, topical benzoyl peroxide, salicylic acid, azelaic acid, and various laser devices and surgical procedures [46,47]. However, the long-term use of oral/topical antibiotics may lead to resistance to antibiotics, the prevalence of which has been increasing [48]. Oral isotretinoin has greater potential risks such as intense dryness, systemic side effects, and birth defects [46].

PDT has been studied extensively in relation to acne vulgaris in recent years (Table 1). PDT has been shown to reduce sebum excretion and the amount of Propionibacterium acnes, and to improve the occlusion of the pilosebaceous orifices by promoting keratinocyte shedding [49]. PDT is a promising treatment modality for acne because it can inhibit sebum production and lead to prolonged remission of acne vulgaris without causing bacterial resistance to antibiotics. However, there is no consensus about the optimum light dosimetry and irradiance for the treatment of acne vulgaris. Given that Propionibacterium acnes produces large amounts of certain porphyrins, especially PPIX and coproporphyrin III, light sources alone with no added photosensitizer also have therapeutic photodynamic potential in the treatment of acne [50]. PDT using blue light has produced excellent clinical results in the reduction of inflammatory acne [51,52]. An open study of the effectiveness of phototherapy for acne vulgaris by Kawada et al. demonstrated that blue light phototherapy significantly decreased acne lesions by $64 \%$ in patients and reduced the number of bacteria in vitro [53]. In a double-blind randomized controlled trial, Kwon et al. treated 35 patients with mild-to-moderate acne with blue and red light-emitting diode devices [54]. Eighteen patients received 420-nm blue light and 660-nm red light for 2.5 min twice daily for 4 weeks as a single treatment; the other 17 patients, the control group, were treated with a sham device. During the final visit at 12 weeks, significant reductions of both inflammatory and noninflammatory acne lesions were observed, by $77 \%$ and $54 \%$, respectively, in the light-treated group. Histopathology showed reductions in inflammatory cells and decreased sizes of sebaceous glands [54].

Hongcharu et al. reported the first clinical trial using ALA in the treatment of inflammatory acne vulgaris. In that study, 22 patients with inflammatory acne vulgaris had their face treated for an incubation time of $3 \mathrm{~h}$ followed by a 550-700-nm broadband light source. The number of inflammatory acne lesions and sebum secretion levels were significantly reduced after four treatment sessions at the 20-week follow-up [55]. Hongcharu et al. also reported histological evidence of the destruction of sebaceous glands, suggesting that one mechanism of action of PDT in acne treatment involves phototoxic effects on sebaceous follicles, inhibitions of sebaceous gland functions, and significant decreases in the number of bacteria. 
Table 1. Clinical studies of topical PDT for the treatment of acne vulgaris.

\begin{tabular}{|c|c|c|c|c|c|}
\hline $\begin{array}{c}\text { First } \\
\text { Author, } \\
\text { Year } \\
\text { [Reference] }\end{array}$ & $\begin{array}{l}\text { Type of Acne } \\
\text { and Location }\end{array}$ & $\begin{array}{l}\text { Number } \\
\text { of } \\
\text { Patients }\end{array}$ & $\begin{array}{l}\text { Photosensitizer } \\
\text { (Contact Time)/ } \\
\text { Light Source }\end{array}$ & $\begin{array}{l}\text { Number of } \\
\text { Treatment } \\
\text { Sessions } \\
\text { (Follow-up } \\
\text { Time) } \\
\end{array}$ & Clinical Results \\
\hline $\begin{array}{c}\text { Hongcharu, } \\
2000[55]\end{array}$ & $\begin{array}{l}\text { Inflammatory, } \\
\text { mild to } \\
\text { moderate/back }\end{array}$ & 22 & $\begin{array}{l}20 \% \text { ALA } \\
(3 \mathrm{~h}) / \mathrm{red} \text { light } \\
(550-570 \mathrm{~nm}) v s . \\
\text { red light only } v s . \\
\text { placebo }\end{array}$ & $\begin{array}{l}\text { Two } \\
\text { randomized } \\
\text { groups: } 1 \text { vs. } \\
4 \text { sessions } \\
\text { (20 weeks) }\end{array}$ & $\begin{array}{l}\text { ALA-PDT } 1 \text { session better than red } \\
\text { light alone; After } 20 \text { weeks, } 50 \% \\
\text { reduction of lesions after } 4 \text { sessions } \\
\text { vs. } \sim 30 \% \text { reduction with } 1 \text { session }\end{array}$ \\
\hline $\begin{array}{c}\text { Itoh, } \\
2001[56]\end{array}$ & $\begin{array}{l}\text { Comedonal or } \\
\text { inflammatory/ } \\
\text { face }\end{array}$ & 13 & $\begin{array}{c}20 \% \text { ALA }(4 \mathrm{~h}) / \\
\text { broad-spectrum } \\
(600-700 \mathrm{~nm}) \\
\text { halogen lamp }\end{array}$ & $\begin{array}{c}1 \\
\text { (24 weeks) }\end{array}$ & $\begin{array}{l}\text { After } 1 \text { month, } 100 \% \text { some } \\
\text { improvement without new lesions; } \\
\text { at } 3 \text { months, } 38.4 \% \text { "excellent" } \\
\text { response without new lesions }\end{array}$ \\
\hline $\begin{array}{l}\text { Goldman, } \\
2003 \text { [52] }\end{array}$ & $\begin{array}{l}\text { Inflammatory, } \\
\text { mild to } \\
\text { moderate/face }\end{array}$ & 22 & $\begin{array}{c}20 \% \text { ALA } \\
(15 \mathrm{~min}) / \text { blue light } \\
(417 \pm 5 \mathrm{~nm}) v s . \\
\text { blue light only }\end{array}$ & 2 (2 weeks) & $\begin{array}{l}\text { Reductions in inflammatory lesions: } \\
68 \% \text { with ALA-PDT vs. } 40 \% \text { with } \\
\text { blue light only }\end{array}$ \\
\hline $\begin{array}{c}\text { Hong, } \\
2005 \text { [57] }\end{array}$ & $\begin{array}{l}\text { Inflammatory, } \\
\text { mild to } \\
\text { moderate/face }\end{array}$ & 8 & $\begin{array}{l}20 \% \text { ALA }(4 \mathrm{~h}) / \\
\text { halogen lamp red } \\
(630 \pm 63 \mathrm{~nm})\end{array}$ & $\begin{array}{c}1 \\
\text { (24 months) }\end{array}$ & $\begin{array}{l}\text { Reductions in inflammatory lesions: } \\
41.9 \% \text { in treated sites vs. } 15.4 \% \\
\text { in control }\end{array}$ \\
\hline $\begin{array}{l}\text { Wiegell, } \\
2006[58]\end{array}$ & $\begin{array}{c}\text { Inflammatory/ } \\
\text { Face }\end{array}$ & 15 & $\begin{array}{c}20 \% \text { ALA vs. } \\
16.8 \% \text { MAL }(3 \mathrm{~h}) / \\
\text { noncoherent red } \\
(630 \mathrm{~nm})\end{array}$ & $\begin{array}{c}1 \\
\text { (12 weeks) }\end{array}$ & $\begin{array}{l}\text { Reductions in inflammatory lesions: } \\
59 \% \text { with both ALA and MAL; no } \\
\text { significant difference between } \\
\text { MAL and ALA sites }\end{array}$ \\
\hline $\begin{array}{c}\text { Rojanamatin, } \\
2006 \text { [59] }\end{array}$ & $\begin{array}{c}\text { Inflammatory/ } \\
\text { face }\end{array}$ & 14 & $\begin{array}{l}20 \% \text { ALA } \\
(30 \mathrm{~min}) / \mathrm{IPL} \\
\text { (cutoff filter, } \\
560-590 \mathrm{~nm} \text { ) }\end{array}$ & $\begin{array}{c}3 \\
\text { (12 weeks) }\end{array}$ & $\begin{array}{l}\text { Reductions in inflammatory lesions: } \\
87.7 \% \text { for ALA-IPL vs. } 66.8 \% \text { for } \\
\text { IPL only; not significantly different }\end{array}$ \\
\hline $\begin{array}{c}\text { Yeung, } \\
2007[60]\end{array}$ & $\begin{array}{c}\text { Inflammatory/ } \\
\text { face }\end{array}$ & 23 & $\begin{array}{l}16.8 \% \mathrm{MAL} \\
(30 \mathrm{~min}) / \mathrm{IPL} \\
(530-750 \mathrm{~nm})\end{array}$ & $\begin{array}{c}4 \\
\text { (12 weeks) }\end{array}$ & $\begin{array}{l}\text { Reductions in inflammatory lesions: } \\
65 \% \text { with MAL-PDT vs. } 23 \% \text { with } \\
\text { IPL only; noninflammatory lesions: } \\
38 \% \text { vs. } 44 \%\end{array}$ \\
\hline $\begin{array}{c}\text { Kim, } \\
2009 \text { [32] }\end{array}$ & $\begin{array}{c}\text { Mild to } \\
\text { moderate/face }\end{array}$ & 16 & $\begin{array}{c}0.06 \% \mathrm{ICG} \\
\text { solution }(30 \mathrm{~min}) / \\
\text { near-infrared diode } \\
\text { laser }(805 \mathrm{~nm}) \\
\end{array}$ & $\begin{array}{c}1 \text { vs. } 3 \\
\text { (8 weeks) }\end{array}$ & $\begin{array}{l}\text { Subjective satisfaction score } \\
\text { significantly higher in } \\
\text { multiple-treatment group compared } \\
\text { with a single-treatment group }\end{array}$ \\
\hline $\begin{array}{c}\text { Jang, } \\
2011[38]\end{array}$ & $\begin{array}{c}\text { Mild to } \\
\text { moderate/face }\end{array}$ & 34 & $\begin{array}{l}\text { IAA }(30 \mathrm{~min}) \text { with } \\
\text { green light } \\
(520 \mathrm{~nm}) \text { vs. ICG } \\
(15 \mathrm{~min}) \text { with } \\
\text { near-infrared } \\
\text { radiation }(805 \mathrm{~nm})\end{array}$ & 5 (3 months) & $\begin{array}{l}\text { Reductions in inflammatory and } \\
\text { noninflammatory lesions and sebum } \\
\text { secretion: significant reductions for } \\
\text { both IAA and ICG; no significant } \\
\text { differences between IAA and ICG }\end{array}$ \\
\hline
\end{tabular}


Table 1. Cont.

\begin{tabular}{|c|c|c|c|c|c|}
\hline $\begin{array}{c}\text { First } \\
\text { Author, } \\
\text { Year } \\
\text { [Reference] }\end{array}$ & $\begin{array}{l}\text { Type of Acne } \\
\text { and Location }\end{array}$ & $\begin{array}{c}\text { Number } \\
\text { of } \\
\text { Patients }\end{array}$ & $\begin{array}{c}\text { Photosensitizer } \\
\text { (Contact Time)/ } \\
\text { Light Source }\end{array}$ & $\begin{array}{c}\text { Number of } \\
\text { Treatment } \\
\text { Sessions } \\
\text { (Follow-up } \\
\text { Time) } \\
\end{array}$ & Clinical Results \\
\hline $\begin{array}{c}\text { Kim, } \\
2012[34]\end{array}$ & $\begin{array}{c}\text { Mild to } \\
\text { moderate/face }\end{array}$ & 4 & $\begin{array}{c}19 \% \\
\text { a,b-chlorophyll } \\
\text { solution } \\
(30-60 \mathrm{~min}) / \mathrm{IPL} \\
(530-750 \mathrm{~nm}) \\
\end{array}$ & 3 (4 weeks) & $\begin{array}{l}\text { All subjects: mild improvement } \\
\text { after three sessions; significant } \\
\text { reduction in lesion count at 1-month } \\
\text { follow-up }\end{array}$ \\
\hline $\begin{array}{c}\text { Kwon, } \\
2013 \text { [54] }\end{array}$ & $\begin{array}{c}\text { Mild to } \\
\text { moderate/face }\end{array}$ & 55 & $\begin{array}{c}\text { None/home use, } \\
\text { combination } \\
\text { blue-red LED } \\
\text { (660 and } 420 \mathrm{~nm}) \\
\text { vs. control } \\
\text { (sham device) }\end{array}$ & $\begin{array}{l}\text { Twice daily } \\
\text { for } 4 \text { weeks } \\
\text { (12 weeks) }\end{array}$ & $\begin{array}{l}\text { At } 12 \text { weeks, reductions in both } \\
\text { inflammatory and noninflammatory } \\
\text { acne lesions }\end{array}$ \\
\hline $\begin{array}{c}\text { Yin, } \\
2014[61]\end{array}$ & $\begin{array}{l}\text { Inflammatory, } \\
\text { moderate to } \\
\text { severe/face }\end{array}$ & 40 & $\begin{array}{c}15 \% \text { ALA } / \text { ablative } \\
\text { fractional Er:YAG } \\
\text { laser }+ \text { red light } \\
(633 \pm 6 \mathrm{~nm}) / 2 \mathrm{~h}\end{array}$ & $\begin{array}{c}\text { PDT: 4; } \\
\text { Er:YAG } \\
\text { laser: } 5 \\
\text { (12 months) }\end{array}$ & $\begin{array}{l}\text { After } 6 \text { months, } 100 \% \text { overall } \\
\text { improvement in inflammatory } \\
\text { lesions; } 80 \% \text { overall improvement } \\
\text { in acne scars without recurrence }\end{array}$ \\
\hline
\end{tabular}

ALA, 5-aminolevulinic acid; MAL, methyl aminolevulinate hydrochloride; IPL, intense pulse light; LED, light-emitting diode; ICG, indocyanine green; IAA, indole-3-acetic acid; Er:YAG, erbium:yttrium aluminium garnet.

Hongcharu et al. reported the first clinical trial using ALA in the treatment of inflammatory acne vulgaris. In that study, 22 patients with inflammatory acne vulgaris had their face treated for an incubation time of $3 \mathrm{~h}$ followed by a 550-700-nm broadband light source. The number of inflammatory acne lesions and sebum secretion levels were significantly reduced after four treatment sessions at the 20-week follow-up [55]. Hongcharu et al. also reported histological evidence of the destruction of sebaceous glands, suggesting that one mechanism of action of PDT in acne treatment involves phototoxic effects on sebaceous follicles, inhibitions of sebaceous gland functions, and significant decreases in the number of bacteria.

In a case study by Itoh et al. using ALA with an incubation time of $4 \mathrm{~h}$ followed by a $635-\mathrm{nm}$ pulsed excimer dye laser in a single patient with intractable acne vulgaris, the treated side remained disease free over the 8-month follow-up period [49]. In a subsequent study, Itoh et al. used a 600-700-nm halogen light source with a fluence of $13 \mathrm{~J} / \mathrm{cm}^{2}$ after an ALA incubation time of $4 \mathrm{~h}$, to treat 13 patients with acne vulgaris. Significant improvement in facial appearance was achieved and new acne lesions were reduced at 1,3, and 6 months following PDT treatment [56]. The clinical improvement was maintained for at least 6 months. Kim et al. reported that Asian patients with acne felt a significant reduction in sebum secretion on the chlorophyll IPL-PDT-treated side compared with the IPL only-treated side [34] (Figure 2).

In a review of PDT studies for acne vulgaris using different light sources with various incubation times, Sakamoto et al. concluded that long-term remission was associated with an incubation time of at 
least $3 \mathrm{~h}$, that ALA-PDT and MAL-PDT with high fluence and red light had similar efficacy, and that red light PDT may be more likely to inhibit and destroy sebaceous glands, resulting in higher response rates [62].

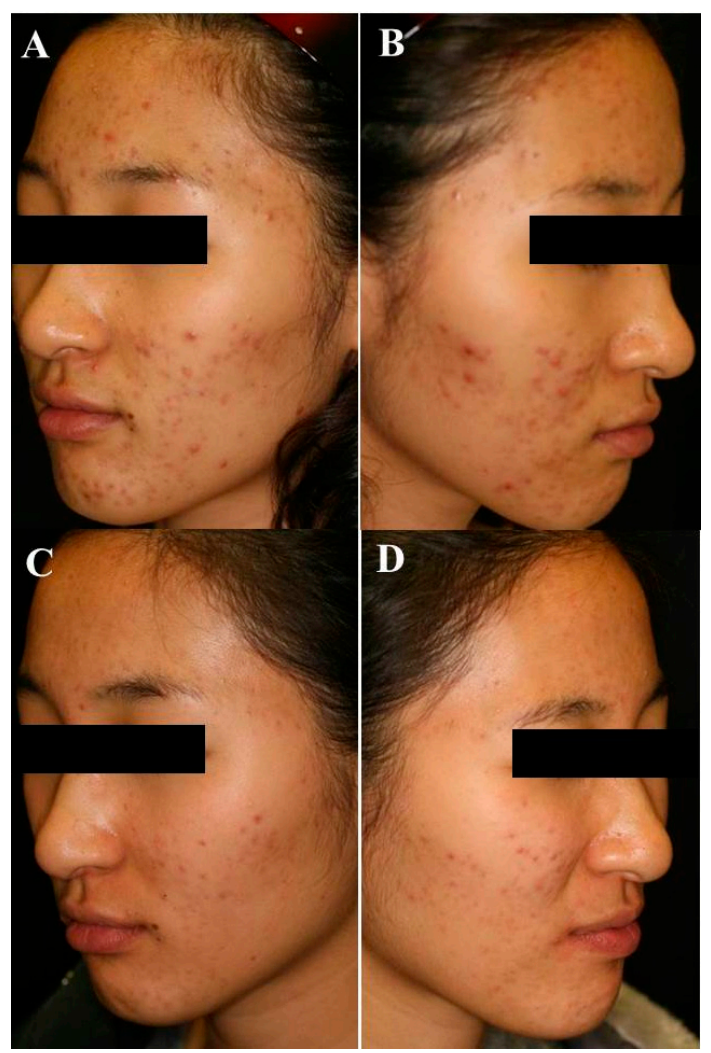

Figure 2. Representative photographs before $(\mathbf{A}, \mathbf{B})$ and after chlorophyll-PDT treatment (C,D). After three treatment sessions of chlorophyll-PDT, there was a significant decrease in the number of papules and pustules in moderate inflammatory acne patient [34].

Moreover, PDT has been shown to be effective in reducing scar formation, and repeated treatment can improve scars, stimulating the wound-healing response. Yin et al. recently conducted a prospective pilot clinical trial to evaluate the efficacy of a combination of ALA-PDT and an ablative fractional erbium:yttrium aluminium garnet (Er:YAG) laser (2940 nm) [61]. Forty patients with severe acne were treated with 15\% ALA-PDT four times, and then received ablative fractional Er:YAG laser treatment five times at one-month intervals. After 12 months, most of the patients had significantly decreased hypertrophic/atrophic scars without recurrence of inflammatory lesions. These findings suggest that ALA-PDT, in combination with ablative fractional Er:YAG laser treatment, may be a successful alternative for controlling the inflammation and decreasing scar formation in the treatment of severe acne.

The first reported clinical trial using MAL was reported by Wiegell and Wulf. They performed a randomized, comparative, investigator-blinded, split-face trial in 21 patients with acne [58]. They compared MAL-PDT with ALA-PDT and found no statistically significant difference in improvements in inflammatory or noninflammatory acne lesion counts at the 12-week follow-up. ALA-PDT caused more prolonged adverse effects such as erythema, edema, and scar formation after treatment. By contrast, Wiegell et al. reported that sites treated with MAL-PDT were less painful than were those treated with ALA-PDT in normal skin [63]. 


\subsection{PDT for Refractory Palmoplantar Warts}

Human papillomaviruses can cause various diseases, including warts, cervical carcinoma, anogenital squamous cell carcinoma, and papillomatosis. Among these conditions, warts are the most common entity caused by this type of virus. Most human papillomaviruses cause specific types of warts in certain anatomical locations, such as plantar warts, common warts, and genital warts. Management of warts is based on their clinical appearance and location, and on the immune status of the patient. The treatment options include surgical excision, cryotherapy, curettage, intralesional bleomycin, $\mathrm{CO}_{2}$ laser therapy, topical cytotoxic medications (5-fluorouracil, dinitrochlorobenzene), infrared coagulation, PDL, PDT, and electrosurgery. However, some lesions remain recalcitrant to therapy, and many recur after successful treatment [64].

Several studies have shown that ALA-PDT can be used to successfully treat cutaneous warts without causing significant side effects and with satisfactory cosmetic results. ALA-PDT with white light (halogen lamp; $250 \mathrm{~W}$ Osram; delivered via slide projector) was found to be more efficacious than red or blue light and standard cryotherapy [65]. One case report described the use of fractional resurfacing to aid PDL-PDT delivery to a recalcitrant plantar wart [66]. Another case report suggested that intralesional administration of ALA with a short incubation period was a safe and effective treatment for recalcitrant warts [67]. One advantage of PDT is the ability to treat a large surface area with minimal scarring.

In a trial reported by Kim et al., intralesional injection (ILI) combined with PDT was used to increase the efficacy of PDT in the treatment of viral warts. Eight patients with multiple viral warts on their hands and feet were treated with IPL after an injection of ALA solution directly into the warts. The wart clearance rates were about $60 \%$ after this treatment (Figure 3). The authors proposed that ILI-PDT may be a new therapeutic strategy for the treatment of thick recalcitrant viral warts [67].

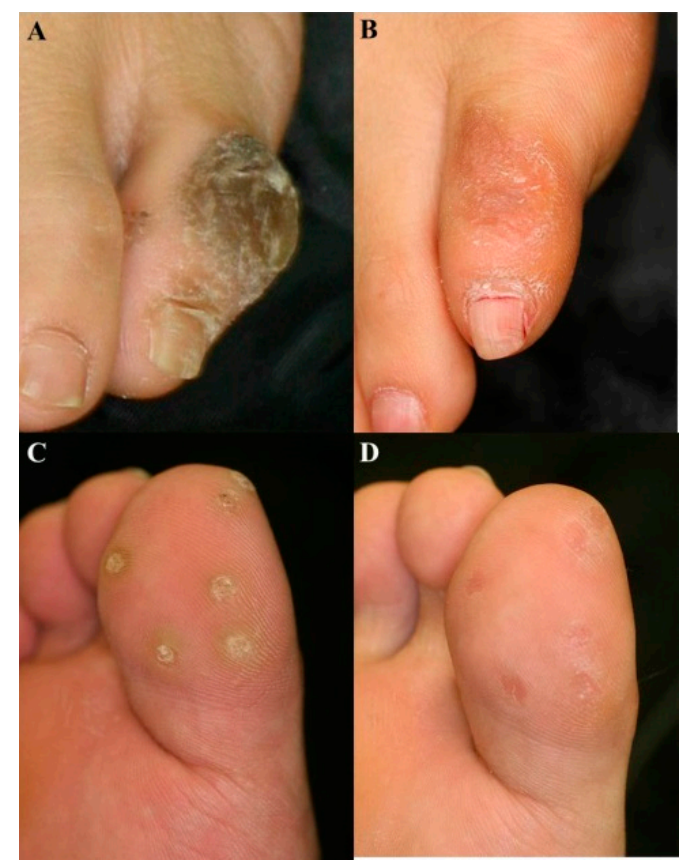

Figure 3. Representative photographs before and after ILI-PDT. Wart lesions on the foot at baseline $(\mathbf{A}, \mathbf{C})$ and 1 month after three sessions of ILI-PDT (B,D). Marked reduction of warts was shown on the great toe and little toe [67]. 
However, few practitioners routinely use PDT for viral warts, possibly because of the lack of a standardized protocol. Clearance rates of recalcitrant hand and foot warts vary between studies, although rates of $56 \%-100 \%$ have been reported. In a randomized trial, six repeated ALA-PDT treatments showed superior results to those of a placebo group; the median reduction in wart area was $98 \%$ with PDT and 52\% with placebo, although PDT induced intense pain in some patients [68]. PDT has been shown to achieve superior clearance compared with cryotherapy in a randomized pilot study of ALA-PDT in 30 patients with recalcitrant warts [65].

The success of ALA-PDT in treating a patient with multiple facial plane warts has been reported, and a recent case series using a 10\% ALA formulation was reported to clear facial warts after two sessions in 17 of 18 patients with only one recurrence after 6 months [69,70]. Complete clearance of periungual hand warts was achieved in 18 of 20 patients (36/40 warts) using ALA-PDT after a mean of 4.5 fortnightly treatments [71]. MAL-PDT was effective in treating a recalcitrant hand wart in a case report, although further studies are needed on its use in warts generally [72].

\subsection{PDT for Genital Warts}

Topical PDT is a treatment option for patients with genital warts. The use of PDT in conjunction with 5-ALA, Photolon ${ }^{\circledR}$ (Belmedpreparaty, Minsk, Republic of Belarus), polyhematoporphyrin, Er:YAG laser, optical parametric oscillator (OPO) laser irradiation, or $\mathrm{CO}_{2}$ laser vaporization has been suggested [73-79]. In a large study of 164 patients with urethral condylomata, ALA-PDT cleared $95 \%$ of lesions, and only 5\% recurred after 6-24 months [80]. A randomized study compared a single treatment of ALA-PDT with a conventional $\mathrm{CO}_{2}$ laser treatment in 65 patients with condyloma acuminata. Clearance rates were $95 \%$ with ALA-PDT and $100 \%$ with the conventional $\mathrm{CO}_{2}$ laser, and the persisting lesions cleared after repeated PDT treatments [73].

In another large randomized clinical trial of ALA-PDT involving 90 patients with condylomata acuminata, all lesions were cleared with both treatment modalities (PDT vs. $\mathrm{CO}_{2}$ laser), although there were fewer recurrences after PDT at 3 months ( $9 \%$ vs. 17\%, respectively) [81]. However, ALA-PDT was not shown to be beneficial as an adjunctive treatment to ablation of condyloma acuminata with a $\mathrm{CO}_{2}$ laser. In a large prospective randomized trial involving 175 patients, the cumulative recurrence rate of the lesions ablated with the $\mathrm{CO}_{2}$ laser in conjunction with ALA-PDT was 50\% vs. 53\% with $\mathrm{CO}_{2}$ laser vaporization alone at the 12-week follow-up [82].

\subsection{PDT for Photorejuvenation}

Photoaging of the skin is a complex, progressive biological process. Clinically, photoaging is characterized by wrinkles, dryness, roughness, laxity, and irregular pigment changes. Recently, PDT delivered with various lasers and light sources, such as IPL, PDL, and blue light-emitting lamps, has been shown to improve photodamaged skin and its associated actinic keratosis and to have excellent cosmetic results $[83,84]$. With the development of short-contact ALA-PDT and synergy between the photochemical effects (ROS) and the photothermal effects (using IPL or PDL), the application of PDT could be extended to the cosmetic field [84].

In a randomized, controlled, split-face study of 25 patients with sun-damaged skin, MAL-PDT followed by irradiation with either an LED $\left(635 \mathrm{~nm}, 37 \mathrm{~J} / \mathrm{cm}^{2}\right)$ or an IPL showed significant 
improvement in wrinkling and mottled pigmentation at 3 months [85]. In a split-face study, IPL-assisted ALA-PDT was compared with IPL alone in 16 patients in a side-by-side setup. IPL-assisted ALA-PDT achieved greater improvements in photodamaged skin and greater clearance of actinic keratosis lesions than did IPL alone. The authors suggested that ALA-PDT may have useful applications for photorejuvenation in the future [86].

Recently, Shin et al. evaluated IPL-PDT and a long-pulsed neodymium-doped yttrium aluminium garnet (Nd:YAG) laser (LPNY) using a 0.5\% ALA liposomal spray for periorbital wrinkles in Asian patients. The patients were exposed to three PDT treatments every 3 weeks and the investigators followed up 3 months after the last treatment. The investigators found greater wrinkle reduction on the IPL-PDT-treated side than on the LPNY-treated side [87]. These results are supported by several studies that showed increases in both collagen production and epidermal proliferation [88]. Marmur et al. reported that PDT using IPL promoted a greater amount of type I collagen than did IPL treatment alone and suggested that PDT is superior to other nonablative laser therapies [89]. Consistent with these other studies, Orringer et al. also found that collagen production and epidermal thickness were increased after ALA-PDT using a PDL [90].

\section{Conclusions}

The use of PDT for the treatment of premalignant and malignant skin lesions, such as actinic keratosis, BCC, and Bowen's disease, is established. The introduction of topical photosensitizers, which are convenient and less phototoxic, has expanded the range of clinical application of PDT in dermatology. There is growing evidence that topical PDT is effective in the treatment of various benign skin conditions including viral warts, photodamaged skin, and acne vulgaris, and especially in lesions that are inflamed or oily and unresponsive to conventional therapies. With increasing concern about bacterial resistance due to the long-term use of oral and topical antibiotics for acne vulgaris, topical PDT is an effective method for treating acne vulgaris because it inhibits sebaceous gland function and reduces the number of bacteria, resulting in prolonged remission of acne vulgaris. In addition, topical PDT effectively improves photodamaged skin, including skin laxity and mottled pigmentation. However, the use of PDT in dermatology has not been optimized. More well-controlled clinical studies of various skin conditions and diseases in a large number of patients with long-term follow-up are needed to standardize the type of light source, wavelength, treatment parameters, and photosensitizer incubation time.

Future advances hold great promise for the treatment of various skin diseases and the combination of PDT with other treatments. Such advances include the targeting of photosensitizers using molecular recognition and incorporation of nanotechnology (i.e., photosensitizer conjugated to nanoparticles); development of further optimizing the ALA derivatives, i.e., not only considering methyl-ALA but also hexyl-ALA or even ALA-DGME; light delivery methods, and dosimetry techniques; use of antimicrobial photoinactivation; and the influence of host immunity.

\section{Acknowledgments}

This work was supported by the Basic Science Research program through the National Research Foundation of Korea (NRF), which is funded by the Ministry of Education, Science and Technology (2012046972). 


\section{Author Contributions}

Miri Kim wrote the manuscript. Haw Young Jung and Hyun Jeong Park assisted in reviewing, rewriting, and revising the manuscript.

\section{Conflicts of Interest}

The authors declare no conflict of interest.

\section{References}

1. Rabb, O. Ueber die wirkung fluoreszierender stoffe auf infusori. Ztg. Biol. 1900, 39, 524-536.

2. Von Tappeiner, H.; Jesionek A. Therapeutische versuche mit fluoreszierenden stoffen. Munch. Med. Wochenschr. 1903, 50, 2042-2044.

3. Dougherty, T.J.; Kaufman, J.E.; Goldfarb, A.; Weishaupt, K.R.; Boyle, D.; Mittleman, A. Photoradiation therapy for the treatment of malignant tumors. Cancer Res. 1978, 38, 2628-2635.

4. Jin, Y.; Zhang, X.; Zhang, B.; Kang, H.; Du, L.; Li, M. Nanostructures of an amphiphilic zinc phthalocyanine polymer conjugate for photodynamic therapy of psoriasis. Colloids Surf. B Biointerfaces 2015, 128, 405-409.

5. Bissonnette, R.; Tremblay, J.F.; Juzenas, P.; Boushira, M.; Lui, H. Systemic photodynamic therapy with aminolevulinic acid induces apoptosis in lesional $\mathrm{T}$ lymphocytes of psoriatic plaques. J. Investig. Dermatol. 2002, 119, 77-83.

6. Karrer, S.; Abels, C.; Wimmershoff, M.B.; Landthaler, M.; Szeimies, R.M. Successful treatment of cutaneous sarcoidosis using topical photodynamic therapy. Arch. Dermatol. 2002, 138, 581-584.

7. Ma, Y.; Liu, Y.; Wang, Q.; Ren, J.; Xiang, L. Prospective study of topical 5-aminolevulinic acid photodynamic therapy for the treatment of severe adolescent acne in Chinese patients. J. Dermatol. 2015, 42, 504-507.

8. Ying, Z.; Li, X.; Dang, H. 5-aminolevulinic acid-based photodynamic therapy for the treatment of condylomata acuminata in Chinese patients: A meta-analysis. Photodermatol. Photoimmunol. Photomed. 2013, 29, 149-159.

9. Enk, C.D.; Nasereddin, A.; Alper, R.; Dan-Goor, M.; Jaffe, C.L.; Wulf, H.C. Cutaneous leishmaniasis responds to daylight-activated photodynamic therapy: Proof of concept for a novel self-administered therapeutic modality. Br. J. Dermatol. 2015, 172, 1364-1370.

10. Brown, S.B.; Brown, E.A.; Walker, I. The present and future role of photodynamic therapy in cancer treatment. Lancet Oncol. 2004, 5, 497-508.

11. Morton, C.A.; Szeimies, R.M.; Sidoroff, A.; Braathen, L.R. European guidelines for topical photodynamic therapy part 1: Treatment delivery and current indications-Actinic keratoses, Bowen's disease, basal cell carcinoma. J. Eur. Acad. Dermatol. Venereol. 2013, 27, 536-544.

12. Mroz, P.; Yaroslavsky, A.; Kharkwal, G.B.; Hamblin, M.R. Cell death pathways in photodynamic therapy of cancer. Cancers (Basel) 2011, 3, 2516-2539.

13. Karrer, S.; Bosserhoff, A.K.; Weiderer, P.; Landthaler, M.; Szeimies, R.M. Keratinocyte-derived cytokines after photodynamic therapy and their paracrine induction of matrix metalloproteinases in fibroblasts. Br. J. Dermatol. 2004, 151, 776-783. 
14. Kennedy, J.C.; Pottier, R.H.; Pross, D.C. Photodynamic therapy with endogenous protoporphyrin IX: Basic principles and present clinical experience. J. Photochem. Photobiol. B Biol. 1990, 6, $143-148$.

15. Iinuma, S.; Farshi, S.S.; Ortel, B.; Hasan, T. A mechanistic study of cellular photodestruction with 5-aminolaevulinic acid-induced porphyrin. Br. J. Cancer 1994, 70, 21-28.

16. Divaris, D.X.; Kennedy, J.C.; Pottier, R.H. Phototoxic damage to sebaceous glands and hair follicles of mice after systemic administration of 5-aminolevulinic acid correlates with localized protoporphyrin IX fluorescence. Am. J. Pathol. 1990, 136, 891-897.

17. Szeimies, R.M.; Landthaler, M. Photodynamic therapy and fluorescence diagnosis of skin cancers. Recent Results Cancer Res. 2002, 160, 240-245.

18. Barr, H.; Kendall, C.; Reyes-Goddard, J.; Stone, N. Clinical aspects of photodynamic therapy. Sci. Prog. 2002, 85, 131-150.

19. Casas, A.; Perotti, C.; Saccoliti, M.; Sacca, P.; Fukuda, H.; Batlle, A.M. ALA and ALA hexyl ester in free and liposomal formulations for the photosensitisation of tumour organ cultures. Br. J. Cancer 2002, 86, 837-842.

20. Di Venosa, G.; Hermida, L.; Batlle, A.; Fukuda, H.; Defain, M.V.; Mamone, L.; Rodriguez, L.; MacRobert, A.; Casas, A. Characterisation of liposomes containing aminolevulinic acid and derived esters. J. Photochem. Photobiol. B Biol. 2008, 92, 1-9.

21. Sadasivam, M.; Avci, P.; Gupta, G.K.; Lakshmanan, S.; Chandran, R.; Huang, Y.Y.; Kumar, R.; Hamblin, M.R. Self-assembled liposomal nanoparticles in photodynamic therapy. Eur. J. Nanomed. 2013, 5, 115-129.

22. Dirschka, T.; Radny, P.; Dominicus, R.; Mensing, H.; Bruning, H.; Jenne, L.; Karl, L.; Sebastian, M.; Oster-Schmidt, C.; Klovekorn, W.; et al. Photodynamic therapy with BF-200 ALA for the treatment of actinic keratosis: Results of a multicentre, randomized, observer-blind phase III study in comparison with a registered methyl-5-aminolaevulinate cream and placebo. Br. J. Dermatol. 2012, 166, 137-146.

23. Xiang, W.; Weingandt, H.; Liessmann, F.; Klein, S.; Stepp, H.; Baumgartner, R.; Hillemanns, P. Photodynamic effects induced by aminolevulinic acid esters on human cervical carcinoma cells in culture. Photochem. Photobiol. 2001, 74, 617-623.

24. Braathen, L.R.; Szeimies, R.M.; Basset-Seguin, N.; Bissonnette, R.; Foley, P.; Pariser, D.; Roelandts, R.; Wennberg, A.M.; Morton, C.A. Guidelines on the use of photodynamic therapy for nonmelanoma skin cancer: An international consensus. International Society for Photodynamic Therapy in Dermatology, 2005. J. Am. Acad. Dermatol. 2007, 56, 125-143.

25. Szeimies, R.M.; Karrer, S.; Radakovic-Fijan, S.; Tanew, A.; Calzavara-Pinton, P.G.; Zane, C.; Sidoroff, A.; Hempel, M.; Ulrich, J.; Proebstle, T.; et al. Photodynamic therapy using topical methyl 5-aminolevulinate compared with cryotherapy for actinic keratosis: A prospective, randomized study. J. Am. Acad. Dermatol. 2002, 47, 258-262.

26. Pariser, D.M.; Lowe, N.J.; Stewart, D.M.; Jarratt, M.T.; Lucky, A.W.; Pariser, R.J.; Yamauchi, P.S. Photodynamic therapy with topical methyl aminolevulinate for actinic keratosis: Results of a prospective randomized multicenter trial. J. Am. Acad. Dermatol. 2003, 48, 227-232. 
27. Tarstedt, M.; Rosdahl, I.; Berne, B.; Svanberg, K.; Wennberg, A.M. A randomized multicenter study to compare two treatment regimens of topical methyl aminolevulinate (Metvix)-PDT in actinic keratosis of the face and scalp. Acta Derm. Venereol. 2005, 85, 424-428.

28. Kuijpers, D.I.; Thissen, M.R.; Thissen, C.A.; Neumann, M.H. Similar effectiveness of methyl aminolevulinate and 5-aminolevulinate in topical photodynamic therapy for nodular basal cell carcinoma. J. Drugs Dermatol. 2006, 5, 642-645.

29. Moloney, F.J.; Collins, P. Randomized, double-blind, prospective study to compare topical 5-aminolaevulinic acid methylester with topical 5-aminolaevulinic acid photodynamic therapy for extensive scalp actinic keratosis. Br. J. Dermatol. 2007, 157, 87-91.

30. Botto, N.; Rogers, G. Nontraditional management of basal cell carcinoma. J. Drugs Dermatol. 2013, 12, 525-532.

31. Fritsch, C.; Homey, B.; Stahl, W.; Lehmann, P.; Ruzicka, T.; Sies, H. Preferential relative porphyrin enrichment in solar keratoses upon topical application of delta-aminolevulinic acid methylester. Photochem. Photobiol. 1998, 68, 218-221.

32. Kim, B.J.; Lee, H.G.; Woo, S.M.; Youn, J.I.; Suh, D.H. Pilot study on photodynamic therapy for acne using indocyanine green and diode laser. J. Dermatol. 2009, 36, 17-21.

33. Barras, A.; Boussekey, L.; Courtade, E.; Boukherroub, R. Hypericin-loaded lipid nanocapsules for photodynamic cancer therapy in vitro. Nanoscale 2013, 5, 10562-10572.

34. Kim, J.E.; Hwang, J.I.; Lee, J.I.; Cho, B.K.; Park, H.J. Pilot study on photodynamic therapy for acne using chlorophyll: Evaluator-blinded, split-face study. J. Dermatol. Treat. 2012, 23, 35-36.

35. Paz-Cristobal, M.P.; Gilaberte, Y.; Alejandre, C.; Pardo, J.; Revillo, M.J.; Rezusta, A. In vitro fungicidal photodynamic effect of hypericin on Trichophyton spp. Mycopathologia 2014, 178, 221-225.

36. Masuda, $\mathrm{T}$. Recent overview of the $\mathrm{Mg}$ branch of the tetrapyrrole biosynthesis leading to chlorophylls. Photosynth. Res. 2008, 96, 121-143.

37. Nyman, E.S.; Hynninen, P.H. Research advances in the use of tetrapyrrolic photosensitizers for photodynamic therapy. J. Photochem. Photobiol. B Biol. 2004, 73, 1-28.

38. Jang, M.S.; Doh, K.S.; Kang, J.S.; Jeon, Y.S.; Suh, K.S.; Kim, S.T. A comparative split-face study of photodynamic therapy with indocyanine green and indole-3-acetic acid for the treatment of acne vulgaris. Br. J. Dermatol. 2011, 165, 1095-1100.

39. Gold, M.H. Therapeutic and aesthetic uses of photodynamic therapy part two of a five-part series: Lasers and light treatments for acne vulgaris promising therapies. J. Clin. Aesthet. Dermatol. 2008, 1, 28-34.

40. Karrer, S.; Baumler, W.; Abels, C.; Hohenleutner, U.; Landthaler, M.; Szeimies, R.M. Long-pulse dye laser for photodynamic therapy: Investigations in vitro and in vivo. Lasers Surg. Med. 1999, $25,51-59$.

41. Itkin, A.; Gilchrest, B.A. delta-Aminolevulinic acid and blue light photodynamic therapy for treatment of multiple basal cell carcinomas in two patients with nevoid basal cell carcinoma syndrome. Dermatol. Surg. 2004, 30, 1054-1061.

42. Barge, J.; Glanzmann, T.; Zellweger, M.; Salomon, D.; van den Bergh, H.; Wagnieres, G. Correlations between photoactivable porphyrins' fluorescence, erythema and the pain induced by PDT on normal skin using ALA-derivatives. Photodiagnosis Photodyn. Ther. 2013, 10, 683-693. 
43. Piffaretti, F.; Zellweger, M.; Kasraee, B.; Barge, J.; Salomon, D.; van den Bergh, H.; Wagnieres, G. Correlation between protoporphyrin IX fluorescence intensity, photobleaching, pain and clinical outcome of actinic keratosis treated by photodynamic therapy. Dermatology (Basel) 2013, 227, 214-225.

44. Borelli, C.; Merk, K.; Schaller, M.; Jacob, K.; Vogeser, M.; Weindl, G.; Berger, U.; Plewig, G. In vivo porphyrin production by $P$. acnes in untreated acne patients and its modulation by acne treatment. Acta Derm. Venereol. 2006, 86, 316-319.

45. Ashkenazi, H.; Malik, Z.; Harth, Y.; Nitzan, Y. Eradication of Propionibacterium acnes by its endogenic porphyrins after illumination with high intensity blue light. FEMS Immunol. Med. Microbiol. 2003, 35, 17-24.

46. Titus, S.; Hodge, J. Diagnosis and treatment of acne. Am. Fam. Physician 2012, 86, 734-740.

47. Thiboutot, D.; Gollnick, H.; Bettoli, V.; Dreno, B.; Kang, S.; Leyden, J.J.; Shalita, A.R.; Lozada, V.T.; Berson, D.; Finlay, A.; et al. New insights into the management of acne: An update from the global alliance to improve outcomes in acne group. J. Am. Acad. Dermatol. 2009, 60, S1-S50.

48. James, W.D. Clinical practice. Acne. N. Engl. J. Med. 2005, 352, 1463-1472.

49. Itoh, Y.; Ninomiya, Y.; Tajima, S.; Ishibashi, A. Photodynamic therapy for acne vulgaris with topical 5-aminolevulinic acid. Arch. Dermatol. 2000, 136, 1093-1095.

50. Johnsson, A.; Kjeldstad, B.; Melo, T.B. Fluorescence from pilosebaceous follicles. Arch. Dermatol. Res. 1987, 279, 190-193.

51. Cunliffe, W.J.; Goulden, V. Phototherapy and acne vulgaris. Br. J. Dermatol. 2000, 142, 855-856.

52. Goldman, M.P.; Boyce, S.M. A single-center study of aminolevulinic acid and 417 NM photodynamic therapy in the treatment of moderate to severe acne vulgaris. J. Drugs Dermatol. 2003, 2, 393-396.

53. Kawada, A.; Aragane, Y.; Kameyama, H.; Sangen, Y.; Tezuka, T. Acne phototherapy with a high-intensity, enhanced, narrow-band, blue light source: An open study and in vitro investigation. J. Dermatol. Sci. 2002, 30, 129-135.

54. Kwon, H.H.; Lee, J.B.; Yoon, J.Y.; Park, S.Y.; Ryu, H.H.; Park, B.M.; Kim, Y.J.; Suh, D.H. The clinical and histological effect of home-use, combination blue-red LED phototherapy for mild-to-moderate acne vulgaris in Korean patients: A double-blind, randomized controlled trial. Br. J. Dermatol. 2013, 168, 1088-1094.

55. Hongcharu, W.; Taylor, C.R.; Chang, Y.; Aghassi, D.; Suthamjariya, K.; Anderson, R.R. Topical ALA-photodynamic therapy for the treatment of acne vulgaris. J. Investig. Dermatol. 2000, 115, 183-192.

56. Itoh, Y.; Ninomiya, Y.; Tajima, S.; Ishibashi, A. Photodynamic therapy of acne vulgaris with topical $\delta$-aminolaevulinic acid and incoherent light in Japanese patients. Br. J. Dermatol. 2001, 144, 575-579.

57. Hong, S.B.; Lee, M.H. Topical aminolevulinic acid-photodynamic therapy for the treatment of acne vulgaris. Photodermatol. Photoimmunol. Photomed. 2005, 21, 322-325.

58. Wiegell, S.R.; Wulf, H.C. Photodynamic therapy of acne vulgaris using 5-aminolevulinic acid versus methyl aminolevulinate. J. Am. Acad. Dermatol. 2006, 54, 647-651.

59. Rojanamatin, J.; Choawawanich, P. Treatment of inflammatory facial acne vulgaris with intense pulsed light and short contact of topical 5-aminolevulinic acid: A pilot study. Dermatol. Surg. 2006, 32, 991-996. 
60. Yeung, C.K.; Shek, S.Y.; Bjerring, P.; Yu, C.S.; Kono, T.; Chan, H.H. A comparative study of intense pulsed light alone and its combination with photodynamic therapy for the treatment of facial acne in Asian skin. Lasers Surg. Med. 2007, 39, 1-6.

61. Yin, R.; Lin, L.; Xiao, Y.; Hao, F.; Hamblin, M.R. Combination ALA-PDT and ablative fractional Er:YAG laser (2940 nm) on the treatment of severe acne. Lasers Surg. Med. 2014, 46, 165-172.

62. Sakamoto, F.H.; Lopes, J.D.; Anderson, R.R. Photodynamic therapy for acne vulgaris: A critical review from basics to clinical practice: Part I. Acne vulgaris: When and why consider photodynamic therapy? J. Am. Acad. Dermatol. 2010, 63, 183-193.

63. Wiegell, S.R.; Stender, I.M.; Na, R.; Wulf, H.C. Pain associated with photodynamic therapy using 5-aminolevulinic acid or 5-aminolevulinic acid methylester on tape-stripped normal skin. Arch. Dermatol. 2003, 139, 1173-1177.

64. Wan, M.T.; Lin, J.Y. Current evidence and applications of photodynamic therapy in dermatology. Clin. Cosmet. Investig. Dermatol. 2014, 7, 145-163.

65. Stender, I.M.; Lock-Andersen, J.; Wulf, H.C. Recalcitrant hand and foot warts successfully treated with photodynamic therapy with topical 5-aminolaevulinic acid: A pilot study. Clin. Exp. Dermatol. 1999, 24, 154-159.

66. Gold, M.H.; Pope, A. Fractional resurfacing aiding photodynamic therapy of a recalcitrant plantar verruca: A case report and review of the literature. J. Clin. Aesthet. Dermatol. 2008, 1, 30-33.

67. Kim, J.E.; Kim, S.J.; Hwang, J.I.; Lee, K.J.; Park, H.J.; Cho, B.K. New proposal for the treatment of viral warts with intralesional injection of 5-aminolevulinic acid photodynamic therapy. J. Dermatol. Treat. 2012, 23, 192-195.

68. Stender, I.M.; Na, R.; Fogh, H.; Gluud, C.; Wulf, H.C. Photodynamic therapy with 5-aminolaevulinic acid or placebo for recalcitrant foot and hand warts: Randomised double-blind trial. Lancet 2000, $355,963-966$.

69. Mizuki, D.; Kaneko, T.; Hanada, K. Successful treatment of topical photodynamic therapy using 5-aminolevulinic acid for plane warts. Br. J. Dermatol. 2003, 149, 1087-1088.

70. Lu, Y.G.; Wu, J.J.; He, Y.; Yang, H.Z.; Yang, Y.D. Efficacy of topical aminolevulinic acid photodynamic therapy for the treatment of verruca planae. Photomed. Laser Surg. 2010, 28, 561-563.

71. Schroeter, C.A.; Kaas, L.; Waterval, J.J.; Bos, P.M.; Neumann, H.A. Successful treatment of periungual warts using photodynamic therapy: A pilot study. J. Eur. Acad. Dermatol. Venereol. 2007, 21, 1170-1174.

72. Chong, W.S.; Kang, G.Y. Dramatic clearance of a recalcitrant acral viral wart using methyl aminolevulinate-red light photodynamic therapy. Photodermatol. Photoimmunol. Photomed. 2009, $25,225-226$.

73. Chen, K.; Chang, B.Z.; Ju, M.; Zhang, X.H.; Gu, H. Comparative study of photodynamic therapy vs. $\mathrm{CO}_{2}$ laser vaporization in treatment of condylomata acuminata: A randomized clinical trial. Br. J. Dermatol. 2007, 156, 516-520.

74. Fehr, M.K.; Chapman, C.F.; Krasieva, T.; Tromberg, B.J.; McCullough, J.L.; Berns, M.W.; Tadir, Y. Selective photosensitizer distribution in vulvar condyloma acuminatum after topical application of 5-aminolevulinic acid. Am. J. Obstet. Gynecol. 1996, 174, 951-957. 
75. Ichimura, H.; Yamaguchi, S.; Kojima, A.; Tanaka, T.; Niiya, K.; Takemori, M.; Hasegawa, K.; Nishimura, R. Eradication and reinfection of human papillomavirus after photodynamic therapy for cervical intraepithelial neoplasia. Int. J. Clin. Oncol. 2003, 8, 322-325.

76. Istomin, Y.P.; Lapzevich, T.P.; Chalau, V.N.; Shliakhtsin, S.V.; Trukhachova, T.V. Photodynamic therapy of cervical intraepithelial neoplasia grades II and III with Photolon. Photodiagnosis Photodyn. Ther. 2010, 7, 144-151.

77. Nucci, V.; Torchia, D.; Cappugi, P. Treatment of anogenital condylomata acuminata with topical photodynamic therapy: Report of 14 cases and review. Int. J. Infect. Dis. 2010, 14 (Suppl. 3), e280-e282.

78. Ross, E.V.; Romero, R.; Kollias, N.; Crum, C.; Anderson, R.R. Selectivity of protoporphyrin IX fluorescence for condylomata after topical application of 5-aminolaevulinic acid: Implications for photodynamic treatment. Br. J. Dermatol. 1997, 137, 736-742.

79. Wang, J.; Xu, J.; Chen, J.; He, Q.; Xiang, L.; Huang, X.; Ding, G.; Xu, S. Successful photodynamic therapy with topical 5-aminolevulinic acid for five cases of cervical intraepithelial neoplasia. Arch. Gynecol. Obstet. 2010, 282, 307-312.

80. Wang, X.L.; Wang, H.W.; Wang, H.S.; Xu, S.Z.; Liao, K.H.; Hillemanns, P. Topical 5-aminolaevulinic acid-photodynamic therapy for the treatment of urethral condylomata acuminata. Br. J. Dermatol. 2004, 151, 880-885.

81. Liang, J.; Lu, X.N.; Tang, H.; Zhang, Z.; Fan, J.; Xu, J.H. Evaluation of photodynamic therapy using topical aminolevulinic acid hydrochloride in the treatment of condylomata acuminata: A comparative, randomized clinical trial. Photodermatol. Photoimmunol. Photomed. 2009, 25, 293-297.

82. Szeimies, R.M.; Schleyer, V.; Moll, I.; Stocker, M.; Landthaler, M.; Karrer, S. Adjuvant photodynamic therapy does not prevent recurrence of condylomata acuminata after carbon dioxide laser ablation-A phase III, prospective, randomized, bicentric, double-blind study. Dermatol. Surg. 2009, 35, 757-764.

83. Zakhary, K.; Ellis, D.A. Applications of aminolevulinic Acid-based photodynamic therapy in cosmetic facial plastic practices. Facial Plast. Surg. 2005, 21, 110-116.

84. Uebelhoer, N.S.; Dover, J.S. Photodynamic therapy for cosmetic applications. Dermatol. Ther. 2005, 18, 242-252.

85. Babilas, P.; Travnik, R.; Werner, A.; Landthaler, M.; Szeimies, R.M. Split-face-study using two different light sources for topical PDT of actinic keratoses: Non-inferiority of the LED system. J. Dtsch. Dermatol. Ges. 2008, 6, 25-32.

86. Gold, M.H.; Bradshaw, V.L.; Boring, M.M.; Bridges, T.M.; Biron, J.A. Split-face comparison of photodynamic therapy with 5 -aminolevulinic acid and intense pulsed light versus intense pulsed light alone for photodamage. Dermatol. Surg. 2006, 32, 795-801.

87. Shin, H.T.; Kim, J.H.; Shim, J.; Lee, J.H.; Lee, D.Y.; Lee, J.H.; Yang, J.M. Photodynamic therapy using a new formulation of 5-aminolevulinic acid for wrinkles in Asian skin: A randomized controlled split face study. J. Dermatolog. Treat. 2015, 26, 246-251.

88. Kohl, E.; Torezan, L.A.; Landthaler, M.; Szeimies, R.M. Aesthetic effects of topical photodynamic therapy. J. Eur. Acad. Dermatol. Venereol. 2010, 24, 1261-1269. 
89. Marmur, E.S.; Phelps, R.; Goldberg, D.J. Ultrastructural changes seen after ALA-IPL photorejuvenation: A pilot study. J. Cosmet. Laser Ther. 2005, 7, 21-24.

90. Orringer, J.S.; Hammerberg, C.; Hamilton, T.; Johnson, T.M.; Kang, S.; Sachs, D.L.; Fisher, G.; Voorhees, J.J. Molecular effects of photodynamic therapy for photoaging. Arch. Dermatol. 2008, $144,1296-1302$.

(C) 2015 by the authors; licensee MDPI, Basel, Switzerland. This article is an open access article distributed under the terms and conditions of the Creative Commons Attribution license (http://creativecommons.org/licenses/by/4.0/). 